\title{
COMÉRCIO SURPRESA: COMPORTAMENTO DE COMPRA DE MYSTERY BOXES
}

\author{
Thauane Lemos de Medeiros ${ }^{1}$, Thalles Vargas², Diana Della \\ Méa da Silva ${ }^{3}$, Steffani Nikoli Dapper ${ }^{4}$
}

\begin{abstract}
RESUMO: 0 mercado de mystery boxes é recente e inovador e possui como uma de suas finalidades despertar diferentes emoções nos consumidores. Em vista disso, o presente estudo teve como objetivo geral analisar o comportamento de compra de mystery boxes dos consumidores da empresa Turista Literário. Para tanto, foi aplicado um instrumento quantitativo com uma amostra de 120 consumidores. Concluiu-se que os associados têm fortes intenções em adquirir uma mystery box. 0 valor agregado em uma mystery box torna a compra vantajosa, visto que os produtos enviados são em edições limitadas e personalizadas conforme os clubes de assinatura. Foi verificado que o consumidor prefere adquirir produtos em uma mystery box e pagar um valor monetário superior, do que adquirir os produtos de forma avulsa e pagar um valor inferior.
\end{abstract}

Palavras-chave: Mystery box, comércio da surpresa, comportamento do consumidor, compra online.

Submissão: 13/05/2019

Aceite: $13 / 08 / 2019$

DOI: $10.47591 / 2674-9203.2019 v 1 n 1 . a r t 2-10-24$

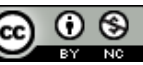

Este trabalho está licenciado com uma Licença Creative Commons Atribuição-NãoComercial 4.0 Internacional.

\footnotetext{
${ }^{1}$ E-mail: thauane.medeiros@hotmail.com

${ }^{2}$ E-mail: vthalles66@gmail.com

${ }^{3}$ E-mail: adm.dianadm@gmail.com

${ }^{4}$ E-mail: steffani.dapper@ fisma.com.br
} 


\section{INTRODUÇÃO}

Mystery boxes são caixas recheadas de itens exclusivos e únicos, enviadas pelo correio por empresas do ramo, para os seus consumidores. 0 sistema consiste em um plano de adesão, que pode ser mensal, bimestral, trimestral ou anual. Para adquirir o produto, o consumidor realiza uma assinatura e recebe, periodicamente, em sua casa, uma caixa repleta de itens surpresas. Em alguns casos, as empresas divulgam spoiler alert em sites e plataformas virtuais do que está por vir na sua próxima edição.

No Brasil, as mysterys boxes começaram a se espalhar por volta de 2014 (TIMOTEO, 2016). Seguindo as mesmas características das tradicionais americanas, tem-se a Nerd ao Cubo, que traz itens da cultura geek, além de peças raras e de colecionadores, em que apenas quem contratou o serviço poderá adquirir tais produtos. Em meados de 2014, no Brasil, surgiram muitos clubes de assinatura de diversos temas. Tais clubes enviam para a casa dos seus associados uma caixa repleta de itens raros, únicos, personalizados e até mesmo colecionáveis. Esses clubes são denominados mystery box.

A ideia principal de uma mystery box é de que seu grupo de clientes seja considerado especial e seleto, uma vez que somente quem é assinante de tal mystery box poderá adquirir os produtos selecionados pela curadoria - pessoas escolhidas a cada mês para fazerem a escolha de itens, ou de um item específico que irá compor a mystery box - do clube.

A empresa escolhida para a realização desta pesquisa é a Turista Literário. Ao conceituar o Turista Literário, Martins (2016) salienta que, o Turista Literário é um programa de assinatura que envia todo mês uma caixa contendo um livro lançamento do mês do gênero young adult e outros itens relacionados à história da obra.

O Turista Literário, especificamente, tem a proposta de imersão total na leitura. Seus assinantes recebem na caixa diversos itens com a proposta de aguçar os sentidos e fazer com que o leitor sinta-se vivendo a história contada pelo autor. Já foram enviados itens como: Pão doce, para aguçar o paladar; Incensos e itens aromáticos com a fragrância descrita na obra, para aguçar o olfato; Souvenir com a ideia de que em cada viagem feita, o turista escolhe uma lembrança do lugar para levar para casa; 0 próprio livro, com a função de aguçar o tato e visão; e todos os meses é enviada, por e-mail, a cartilha explicativa aos assinantes, com uma playlist para acesso exclusivo aos turistas pelo aplicativo Spotify , que consiste em um acesso via QR Code.

Além disso, a empresa tem parcerias com as editoras e consegue produzir conteúdo inédito para os assinantes diretamente no site, ofertar edições exclusivas com a arte e diagramação únicas e, em alguns casos, textos publicados pelos autores diretamente aos seus clientes. 0 Turista Literário ainda envia, no primeiro mês de cada cliente, um passaporte de leitura, já que a ideia do clube é a de viajar para um lugar diferente a cada obra lida.

Atualmente existem diversos clubes de mystery box no mercado. A empresa pioneira nesse ramo foi a Loot Crate. Segundo Barba (2015), a Loot Crate é "uma caixa misteriosa de temas geeks". A Loot Crate tem o objetivo de atender, principalmente, o público geek, enviando em suas caixas itens colecionáveis de 
super-heróis, videogames e artigos relacionados à tecnologia. Os brasileiros tem uma boa aceitação quanto à Loot Crate, entretanto, ainda tem-se muita dificuldade em adquirir as caixas, visto que são de origem norte americana e a procura é alta, a ponto de ter lista de espera para a assinatura no clube.

Para os brasileiros que não querem aguardar na fila de espera da tão querida da Loot Crate, tem-se a Nerd ao Cubo, que atende às expectativas dos geeks de plantão. Em geral, a Nerd ao Cubo tem a mesma proposta de negócio da Loot Crate. Assim, como sua concorrente, a Nerd ao Cubo envia em toda caixa itens relacionados à cultura geek e pop, além de ter diversos planos de assinatura, como: mensal, semestral e até mesmo anual.

Mais recentemente, entrou no mercado a GoBox. Um portal de clubes de assinatura criado pelo grupo Abril. Nele, o assinante tem acesso à diversos clubes de assinatura de mystery boxes, podendo escolher, em uma mesma plataforma virtual, diferentes temas de caixas que deseja receber em sua casa. Os temas variam desde clubes de vinhos a clubes específicos de produtos para pets.

Em vista disso, o presente trabalho tem como objetivo geral analisar o comportamento de compra de mystery boxes dos consumidores da empresa Turista Literário. Este estudo se justifica pelo fato de que o número de pesquisas referentes a esse nicho de mercado é reduzido, podendo assim, contribuir para a compreensão do comportamento de compra do consumidor neste ramo de negócio, o qual procura despertar diferentes emoções nos consumidores.

As emoções, segundo Westbrook (1987) possuem um papel fundamental na decisão de compra do consumidor, sendo que desde o final da década de 1980, estudos tem relatado sobre a influência das emoções na satisfação ou na insatisfação dos consumidores.

Para Oliver (1989), a surpresa do consumidor pode ampliar os sentimentos que antecedem a satisfação e, a própria satisfação, mas o seu papel ainda não está claro e, segundo Larán e Rossi (2006), o tema "surpresa" é alvo de estudos na área da psicologia, mas ainda há um número reduzido de publicações que abordam o comportamento de compra do consumidor.

\section{COMPORTAMENTO DO CONSUMIDOR}

Segundo Engel, Blackwell e Miniard (2000), o comportamento do consumidor está diretamente ligado em obter, consumir e dispor de serviços e produtos, inclusive os fatores decisórios que ocorrem antes e depois destas ações, conforme pode ser observado na Figura 1.

Figura 1: Modelo do processo decisório de compra. 


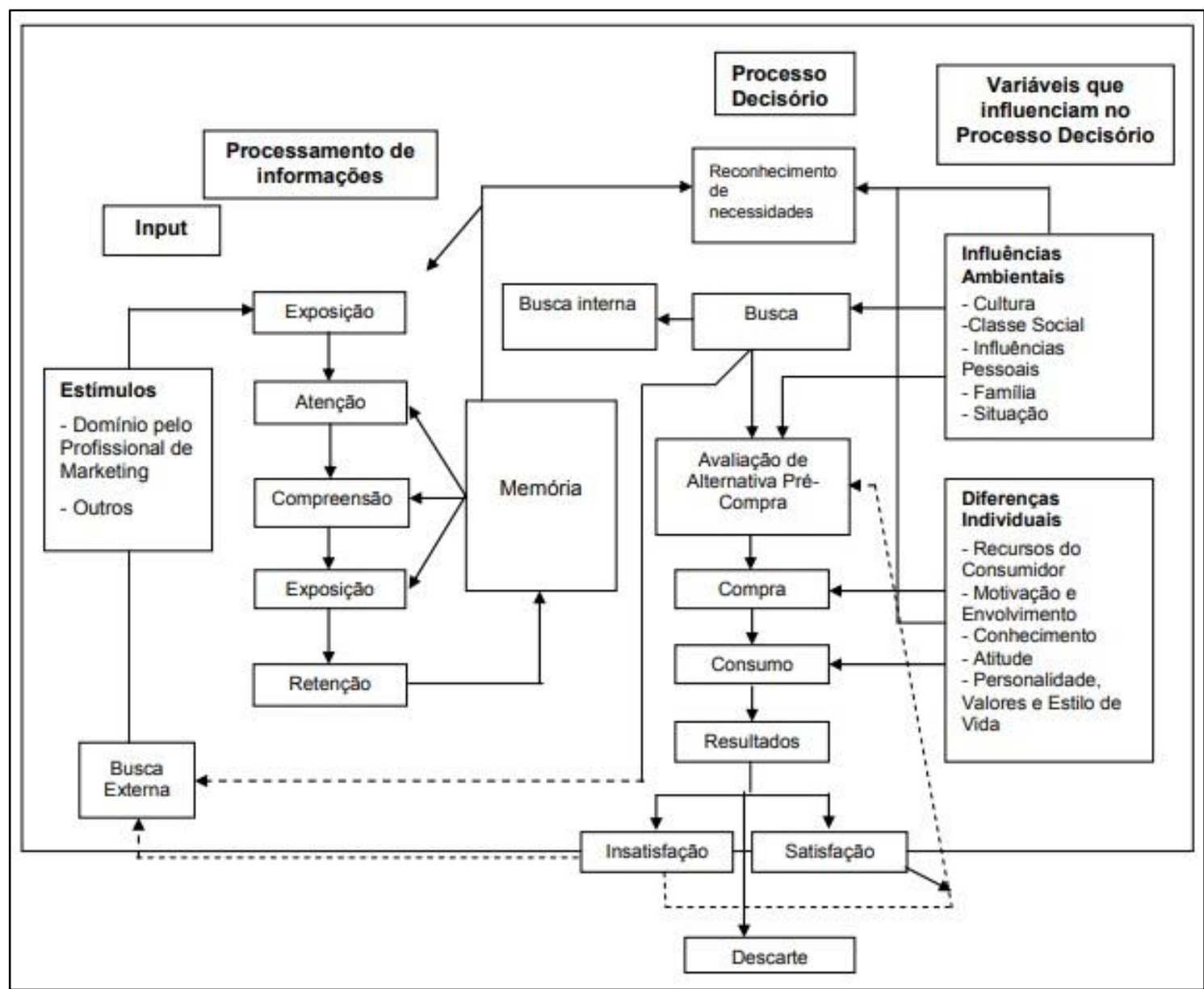

Fonte: Engel, Blackwell e Miniard (2000, p.101)

Estar inserido em um ambiente de trabalho que possibilite ao sujeito se sentir útil, integrado e pertencente a um grupo é investir na promoção de bem-estar e eficácia, entretanto a potencialização desses aspectos é um desafio na contemporaneidade para as organizações (FUNDAÇÃO NACIONAL DA QUALIDADE, 2013). Sendo assim, delineada por meio de uma breve revisão de literatura, discorre-se nessa seção sobre algumas temáticas visando possibilitar um maior entendimento acerca da problemática dessa pesquisa de forma a contextualizar o leitor.

\subsection{GESTÃO ORGANIZACIONAL E BEM-ESTAR DO TRABALHADOR}

O comportamento do consumidor é um conjunto de alguns fatores que influenciam na tomada de decisão, podendo ocasionar na efetivação da compra, ou não. Para Solomon (2015, p. 6), o comportamento do consumidor "é o estudo dos processos envolvidos quando indivíduos ou grupos selecionam, compram, usam, ou descartam produtos, serviços, ideias ou experiências para satisfazerem necessidades ou desejos".

Churchill e Peter (2000) afirmam que o processo de compra do consumidor possui influências sociais bem como situacionais. Engel, Blackwell e Miniard (2000) destacam que as variáveis que influenciam no processo de decisão de compra são 
divididas entre influências ambientais, em diferenças individuais, bem como em fatores pessoais.

Implantar programas de gestão em uma organização não é algo fácil de se fazer, visto que, segundo Gil (2016), considerar o "lado humano da qualidade" (p.286) exige atenção devido à complexidade e amplitude de variáveis envolvidas em cada ser subjetivo.

\section{MÉTODO}

Para a realização desta pesquisa, foram aplicados métodos científicos a fim de se obter resultados satisfatórios e alcançar os objetivos propostos pela pesquisa. Método pode ser definido como "o conjunto das atividades sistemáticas e racionais que, com maior segurança e economia, permite alcançar o objetivo, traçando o caminho a ser seguido, detectando erros e auxiliando as decisões do cientista" (MARCONI; LAKATOS, 2010, p.65).

A fim de atingir os objetivos propostos neste estudo, foi realizada uma pesquisa quantitativa e descritiva. A coleta de dados deu-se por meio de um questionário, o qual foi aplicado aos consumidores de mistery box, sendo disponibilizado em uma rede de contatos própria da empresa Turista Literário.

A amostra de respondentes foi de 120 clientes da empresa. A escolha da empresa Turista Literário como fonte de dados deu-se devido ao fácil acesso pela pesquisadora e pelos objetivos da empresa se enquadrarem à pesquisa em questão.

O questionário foi aplicado com o auxílio do Google forms aos consumidores da empresa Turista Literário e é adaptado de Grupta e Kim apud Abelim (2010). A partir deste questionário foram avaliados cinco construtos decisórios no processo de compra de mystery boxes, os quais são eles: Intenção da compra, Valor percebido, Preço percebido, Risco percebido, Conveniência. Os respondentes puderam assinalar de 1(um) a 5(cinco), sendo 1: Concordo fortemente; 2: Concordo; 3: Nem discordo nem concordo; 4: Discordo; 5: Discordo fortemente.

O questionário consta no Anexo A deste estudo. A aplicação ocorreu no primeiro semestre de 2018. Após aplicado, o questionário foi analisado por meio do software Excel.

\section{RESULTADOS}

O instrumento avalia cinco construtos decisórios no processo de compra de mystery boxes. Após a análise feita, este instrumento possibilitará aos empreendedores deste nicho maiores informações quanto aos principais fatores que levam seus consumidores a adquirir tais produtos, bem como auxiliar na tomada de decisão.

\subsection{INTENCÃO DA COMPRA}

O primeiro construto avalia a intenção do consumidor em comprar uma mystery box. Como pode ser observado no Quadro 1, 108 de um total de 120 respondentes considera a possibilidade de comprar uma mystery box. Apenas 9 dos 
respondentes não tem um posicionamento e 3 dos respondentes não considera comprar uma mystery box.

Quadro 1 - Se eu fosse comprar um produto, eu consideraria a possibilidade de comprar uma mystery box

\begin{tabular}{|c|c|c|}
\hline Variações da Escala & Frequência & $\%$ \\
\hline Concordo fortemente & 58 & $48,3 \%$ \\
\hline Concordo & 50 & $41,7 \%$ \\
\hline Nem discordo nem concordo & 9 & $7,5 \%$ \\
\hline Discordo & 3 & $2,5 \%$ \\
\hline Discordo fortemente & 0 & $0,0 \%$ \\
\hline
\end{tabular}

Fonte: Elaboração dos autores.

Em seguida, foi questionado ao cliente quanto à possibilidade de o mesmo comprar uma mystery box. Observou-se que nenhum dos clientes discorda ou discorda fortemente de que há grande possibilidade de adquirir uma mystery box, sendo que no Quadro 2 pode ser observado que 95,9\% dos respondentes concorda com o questionamento e apenas 4,1\% não tem um posicionamento efetivo.

Quadro 2 - Há grande possibilidade de eu comprar uma mystery box.

\begin{tabular}{|c|c|c|}
\hline Variações da Escala & Frequência & $\%$ \\
\hline Concordo fortemente & 68 & $56,7 \%$ \\
\hline Concordo & 47 & $39,2 \%$ \\
\hline Nem discordo nem concordo & 5 & $4,1 \%$ \\
\hline Discordo & 0 & $0,0 \%$ \\
\hline Discordo fortemente & 0 & $0,0 \%$ \\
\hline
\end{tabular}

Fonte: Elaboração dos autores.

Quando questionados quanto a sua vontade de comprar uma mystery box, 112 de um total de 120 respondentes avaliam que sua vontade de comprar uma mystery box é grande, sendo que 93,4\% concorda ou concorda fortemente com o questionamento, 5,8\% não tem um posicionamento e 0,8\% discorda da afirmação, como pode ser observado no Quadro 3.

Quadro 3 - Minha vontade de comprar uma mystery box é grande.

\begin{tabular}{|c|c|c|}
\hline Variações da Escala & Frequência & $\%$ \\
\hline Concordo fortemente & 74 & $61,7 \%$ \\
\hline Concordo & 38 & $31,7 \%$ \\
\hline Nem discordo nem concordo & 7 & $5,8 \%$ \\
\hline
\end{tabular}




\begin{tabular}{|c|c|c|}
\hline Discordo & 1 & $0,8 \%$ \\
\hline Discordo fortemente & 0 & $0,0 \%$ \\
\hline
\end{tabular}

Fonte: Elaboração dos autores.

No Quadro 4 pode-se observar que 109 de um total de 120 respondentes concordam que há grande probabilidade de comprar uma mystery box. Sendo que destes, 43 respondentes concordam e 66 respondentes concordam fortemente. Os 11 respondentes restantes discordam ou não tem um posicionamento quanto ao questionamento.

Quadro 4 - A probabilidade de eu considerar comprar uma mystery box é grande.

\begin{tabular}{|c|c|c|}
\hline Variações da Escala & Frequência & $\%$ \\
\hline Concordo fortemente & 66 & $55 \%$ \\
\hline Concordo & 43 & $35,8 \%$ \\
\hline Nem discordo nem concordo & 9 & $7,5 \%$ \\
\hline Discordo & 2 & $1,7 \%$ \\
\hline Discordo fortemente & 0 & $0,0 \%$ \\
\hline
\end{tabular}

Fonte: Elaboração dos autores.

A avaliação do primeiro construto conclui que há fortes intenções de compra de mystery box por parte dos respondentes. Sendo que houveram baixos índices de respondentes que discordaram ou discordaram fortemente das afirmativas e poucos respondentes que não se posicionaram quanto aos questionamentos.

\subsection{VALOR PERCEBIDO}

0 segundo construto avalia o valor percebido ao adquirir uma mystery box. Neste momento, os respondentes são questionados quanto ao tempo, esforço, custo, riscos, e investimento relacionados à compra de uma mystery box.

No Quadro 5, tem-se os resultados do questionamento quanto ao tempo e esforço depositados em uma compra de mystery box. Quando questionados quanto ao tempo e esforço relacionados à compra de uma mystery box, 102 respondentes consideram compensatória a efetivação da compra, 11 dos respondentes não se posicionaram e 7 discordam da afirmativa.

Quadro 5 - Considerando o tempo e o esforço, vale a pena comprar uma mystery box.

\begin{tabular}{|c|c|c|}
\hline Variações da Escala & Frequência & $\%$ \\
\hline Concordo fortemente & 66 & $55 \%$ \\
\hline Concordo & 43 & $35,8 \%$ \\
\hline Nem discordo nem concordo & 9 & $7,5 \%$ \\
\hline
\end{tabular}




\begin{tabular}{|c|c|c|}
\hline Discordo & 2 & $1,7 \%$ \\
\hline Discordo fortemente & 0 & $0,0 \%$ \\
\hline
\end{tabular}

Fonte: Elaboração dos autores.

No momento em que foram questionados se o risco da compra é compensatório para a efetivação da aquisição de uma mystery box, 91 respondentes considera o risco de compra compensatório, ou seja, para a maioria dos respondentes os riscos envolvidos na compra não os impedem de adquirir o produto. Entretanto, 19,2\% dos respondentes não souberam se posicionar quanto à afirmação, e 5\% dos respondentes consideram que os riscos envolvidos são um empecilho na decisão de compra de uma mystery box, como é destacado no Quadro 6.

Quadro 6 - Considerando o risco na compra, vale a pena comprar uma mystery box.

\begin{tabular}{|c|c|c|}
\hline Variações da Escala & Frequência & $\%$ \\
\hline Concordo fortemente & 34 & $28,3 \%$ \\
\hline Concordo & 57 & $47,5 \%$ \\
\hline Nem discordo nem concordo & 23 & $19,2 \%$ \\
\hline Discordo & 6 & $5 \%$ \\
\hline Discordo fortemente & 0 & $0,0 \%$ \\
\hline
\end{tabular}

Fonte: Elaboração dos autores.

No Quadro 7 pode-se verificar que ao ser afirmado que é um bom negócio comprar uma mystery box, considerando o valor pago pela compra do produto, 86 dos respondentes concordam com tal afirmativa. Dos 34 respondentes restantes, $73,53 \%$ não se posicionaram e $26,47 \%$ consideram que o valor pago pela compra não compensa o produto. Como é exposto no Quadro 7.

Quadro 7 - Considerando o dinheiro que eu pago pela compra do produto, é um bom negócio comprar uma mystery box.

\begin{tabular}{|c|c|c|}
\hline Variações da Escala & Frequência & $\%$ \\
\hline Concordo fortemente & 40 & $33,3 \%$ \\
\hline Concordo & 46 & $38,3 \%$ \\
\hline Nem discordo nem concordo & 25 & $20,8 \%$ \\
\hline Discordo & 9 & $7,5 \%$ \\
\hline Discordo fortemente & 0 & $0,0 \%$ \\
\hline
\end{tabular}

Fonte: Elaboração dos autores.

No Quadro 8 pode ser observado que 94 dos respondentes considera a compra de mystery box vantajosa mesmo ponderando sobre o esforço e custo investido. Entre um total de 120 respondentes, 76,7\% concordam ou concordam 
fortemente com a afirmativa, $15 \%$ não souberam se posicionar, e apenas $8,3 \%$ discordam ou discordam fortemente.

Quadro 8 - Considerando todo o esforço e custo investido para comprar uma mystery box, esta compra é vantajosa.

\begin{tabular}{|c|c|c|}
\hline Variações da Escala & Frequência & $\%$ \\
\hline Concordo fortemente & 39 & $32,5 \%$ \\
\hline Concordo & 53 & $44,2 \%$ \\
\hline Nem discordo nem concordo & 18 & $15 \%$ \\
\hline Discordo & 9 & $7,5 \%$ \\
\hline Discordo fortemente & 1 & $0,8 \%$ \\
\hline
\end{tabular}

Fonte: Elaboração dos autores.

Após feita a análise deste construto, observa-se que os respondentes consideram que o valor percebido na compra de uma mystery box satisfaz as necessidades e torna vantajosa a compra do produto.

\subsection{PREÇO PERCEBIDO}

Neste momento, os respondentes são questionados quanto ao preço pago por uma mystery box, com relação ao preço que seria pago pelos produtos que são enviados se comprados individualmente.

No Quadro 9 nota-se que 31 respondentes não souberam se posicionar quanto à oportunidade de receber descontos ao comprar os mesmos produtos enviados em uma mystery box de forma avulsa e $45 \%$ dos respondentes concordam ou concordam fortemente que é possível obter descontos na compra de produtos avulsos, enquanto $29,2 \%$ discordam ou discordam fortemente da afirmativa.

Quadro 9 - Pode ser possível obter um desconto, maior em produtos avulsos (fora da mystery box).

\begin{tabular}{|l|c|c|}
\hline \multicolumn{1}{|c|}{ Variações da Escala } & Frequência & $\%$ \\
\hline Concordo fortemente & 14 & $11,7 \%$ \\
\hline Concordo & 40 & $33,3 \%$ \\
\hline Nem discordo nem concordo & 31 & $25,8 \%$ \\
\hline Discordo & 27 & $22,5 \%$ \\
\hline Discordo fortemente & 8 & $6,7 \%$ \\
\hline
\end{tabular}

Fonte: Elaboração dos autores.

Quando questionados se há a possibilidade de ser mais barato comprar um produto avulso, 34 dos respondentes não concordam com a afirmativa, conforme pode ser observado no Quadro 10 . Verificou-se que 52,5\% dos respondentes concordam ou concordam fortemente com a afirmativa, e 19,2\% nem concordam nem discordam. 
Quadro 10 - Pode ser mais barato comprar um produto avulso (fora da mystery box).

\begin{tabular}{|c|c|c|}
\hline Variações da Escala & Frequência & $\%$ \\
\hline Concordo fortemente & 16 & $13,3 \%$ \\
\hline Concordo & 47 & $39,2 \%$ \\
\hline Nem discordo nem concordo & 23 & $19,2 \%$ \\
\hline Discordo & 27 & $22,5 \%$ \\
\hline Discordo fortemente & 7 & $5,8 \%$ \\
\hline
\end{tabular}

Fonte: Elaboração dos autores.

O próximo questionamento deu-se em função de o respondente economizar dinheiro comprando produtos avulsos e não em uma mystery box. De acordo com o Quadro 11, 38 dos respondentes não acreditam que economizariam dinheiro comprando os mesmos produtos que são enviados em uma mystery box de forma avulsa. Verificou-se que exatos $50 \%$ dos respondentes acreditam que economizariam dinheiro comprando os produtos de forma avulsa, e 18,3\% não concordam nem discordam da afirmação.

Quadro 11 - Provavelmente eu economizaria dinheiro comprando um produto avulso (fora da mystery box).

\begin{tabular}{|c|c|c|}
\hline Variações da Escala & Frequência & $\%$ \\
\hline Concordo fortemente & 13 & $10,8 \%$ \\
\hline Concordo & 47 & $39,2 \%$ \\
\hline Nem discordo nem concordo & 22 & $18,3 \%$ \\
\hline Discordo & 27 & $22,5 \%$ \\
\hline Discordo fortemente & 11 & $9,2 \%$ \\
\hline
\end{tabular}

Fonte: Elaboração dos autores.

Ao serem questionados quanto a possibilidade de pagar mais caro comprando produtos em uma mystery box, 64 dos 120 respondentes afirmam que pagam um valor superior comprando produtos em uma mystery box, como é exposto no Quadro 12 . Verificou-se que $23,3 \%$ dos respondentes não concordam nem discordam com a afirmativa, 20,8\% discordam e apenas 2,5\% discordam fortemente.

Quadro 12 - Posso ter que pagar mais caro comprando produtos em uma mystery box.

\begin{tabular}{|c|c|c|}
\hline Variações da Escala & Frequência & $\%$ \\
\hline Concordo fortemente & 18 & $15 \%$ \\
\hline Concordo & 46 & $38,3 \%$ \\
\hline
\end{tabular}




\begin{tabular}{|c|c|c|}
\hline Nem discordo nem concordo & 28 & $23,3 \%$ \\
\hline Discordo & 25 & $20,8 \%$ \\
\hline Discordo fortemente & 03 & $2,5 \%$ \\
\hline
\end{tabular}

Fonte: Elaboração dos autores.

Ao concluir a análise do terceiro construto, preço percebido, verificou-se que a maior parte dos respondentes acredita que pagaria um valor inferior comprando os mesmos produtos que são enviados em uma mystery box de forma avulsa.

\subsection{RISCO PERCEBIDO}

Neste construto, avaliou-se a percepção dos respondentes quanto ao risco percebido na efetivação de compra de uma mystery box. No Quadro 13 pode-se verificar a percepção dos respondentes quanto à existência do risco elevado na compra de uma mystery box. Observa-se que 35,8\% tem conhecimento do risco elevado na compra de uma mystery box, e 43,3\% discordam ou discordam fortemente da afirmação. Já $20,8 \%$ não souberam se posicionar quanto ao questionamento.

Quadro 13 - Comprar mystery box envolve um risco elevado.

\begin{tabular}{|c|c|c|}
\hline Variações da Escala & Frequência & $\%$ \\
\hline Concordo fortemente & 18 & $15 \%$ \\
\hline Concordo & 46 & $38,3 \%$ \\
\hline Nem discordo nem concordo & 28 & $23,3 \%$ \\
\hline Discordo & 25 & $20,8 \%$ \\
\hline Discordo fortemente & 03 & $2,5 \%$ \\
\hline
\end{tabular}

Fonte: Elaboração dos autores.

Quando afirmado que existe uma significativa chance de perda ao adquirir uma mystery box, 60 respondentes discordam ou discordam fortemente, conforme pode-se verificar no Quadro 14. Os 60 respondentes restantes fragmentaram-se entre $22,5 \%$ que não concordam nem discordam, $21,7 \%$ que concordam e 5,8\% que concordam fortemente com a afirmação.

Quadro 14 - Existe uma significativa chance de perda ao comprar uma mystery box.

\begin{tabular}{|l|c|c|}
\hline \multicolumn{1}{|c|}{ Variações da Escala } & Frequência & $\%$ \\
\hline Concordo fortemente & 7 & $5,8 \%$ \\
\hline Concordo & 26 & $21,7 \%$ \\
\hline Nem discordo nem concordo & 27 & $22,5 \%$ \\
\hline
\end{tabular}




\begin{tabular}{|l|c|c|}
\hline Discordo & 48 & $40 \%$ \\
\hline Discordo fortemente & 12 & $10 \%$ \\
\hline
\end{tabular}

Fonte: Elaboração dos autores.

Exatos $50 \%$ dos respondentes concordam que podem haver problemas ao comprar uma mystery box. $23,3 \%$ não souberam se posicionar quanto à afirmação e $26,7 \%$ discordam ou discordam fortemente da afirmação, conforme pode ser observado no Quadro 15.

Quadro 15 - Pode haver problemas ao comprar uma mystery box.

\begin{tabular}{|c|c|c|}
\hline Variações da Escala & Frequência & $\%$ \\
\hline Concordo fortemente & 7 & $5,8 \%$ \\
\hline Concordo & 53 & $44,2 \%$ \\
\hline Nem discordo nem concordo & 28 & $23,3 \%$ \\
\hline Discordo & 23 & $19,2 \%$ \\
\hline Discordo fortemente & 9 & $7,5 \%$ \\
\hline
\end{tabular}

Fonte: Elaboração dos autores.

Ao ser afirmado que as informações pessoais e referentes aos cartões de crédito não estão seguras no comércio online de mystery box, o público respondente ficou dividido entre os que discordam da afirmação, e os que não se posicionaram somados aos que concordam da afirmativa, como é exposto no Quadro 16.

Neste questionamento, $50 \%$ dos respondentes discordam ou discordam fortemente da afirmação de que seus dados não estão seguros no comércio online de compra de mystery box. Já 37 respondentes, equivalentes a 30,8\% não souberam se posicionar quanto à segurança de seus dados, e apenas 19,2\% concorda que seus dados podem não estar seguros no comércio de mystery box, conforme Quadro 16.

Quadro 16 - Meu cartão de créditos e informações pessoais podem não estar seguros em comércio online de mystery box.

\begin{tabular}{|l|c|c|}
\hline \multicolumn{1}{|c|}{ Variações da Escala } & Frequência & $\%$ \\
\hline Concordo fortemente & 3 & $2,5 \%$ \\
\hline Concordo & 20 & $16,7 \%$ \\
\hline Nem discordo nem concordo & 37 & $30,8 \%$ \\
\hline Discordo & 45 & $37,5 \%$ \\
\hline Discordo fortemente & 15 & $12,5 \%$ \\
\hline
\end{tabular}

Fonte: Elaboração dos autores.

Ao finalizar a análise do quarto construto, percebe-se que os respondentes não consideram o risco percebido um fator influente para a decisão de compra de uma mystery box, visto que quando questionados sobre a existência do risco, a 
maioria dos respondentes optou por não se posicionar ou discordou da existência do risco de compra.

\subsection{CONVENIÊNCIA}

0 quinto construto avalia a percepção dos respondentes quanto à conveniência da compra de uma mystery box. A primeira afirmação em que os respondentes são submetidos é quanto à economia de tempo ao comprar um produto pela internet. Neste questionamento, 113 dos 120 respondentes concordam ou concordam fortemente, conforme pode ser observado no Quadro 17 e, apenas 3,3\% dos respondentes discordam da afirmação, enquanto 2,5\% não souberam se posicionar.

Quadro 17 - Comprar pela internet economiza tempo.

\begin{tabular}{|l|c|c|}
\hline \multicolumn{1}{|c|}{ Variações da Escala } & Frequência & $\%$ \\
\hline Concordo fortemente & 71 & $59,2 \%$ \\
\hline Concordo & 42 & $35 \%$ \\
\hline Nem discordo nem concordo & 3 & $2,5 \%$ \\
\hline Discordo & 4 & $3,3 \%$ \\
\hline Discordo fortemente & 0 & $0,0 \%$ \\
\hline
\end{tabular}

Fonte: Elaboração dos autores.

Quanto à afirmação de que comprar pela internet é um péssimo investimento, não houve nenhum respondente que concordasse com a situação, conforme o Quadro 18. Foi verificado um alto índice de respondentes que discordaram da afirmação e o baixo índice de respondentes que optaram por não se posicionar quanto ao exposto.

Quadro 18 - Comprar pela internet é um péssimo investimento.

\begin{tabular}{|l|c|c|}
\hline \multicolumn{1}{|c|}{ Variações da Escala } & Frequência & $\%$ \\
\hline Concordo fortemente & 0 & $0,0 \%$ \\
\hline Concordo & 0 & $0,0 \%$ \\
\hline Nem discordo nem concordo & 5 & $4,1 \%$ \\
\hline Discordo & 62 & $51,7 \%$ \\
\hline Discordo fortemente & 53 & $44,2 \%$ \\
\hline
\end{tabular}

Fonte: Elaboração dos autores.

No Quadro 19, tem-se que a grande maioria dos respondentes considera a compra pela internet fácil, sendo que $98,4 \%$ dos respondentes concorda ou concorda fortemente que a compra pela internet é fácil, 1,7\% dos respondentes não 
se posicionou frente ao exposto e os dados de respondentes que discordam ou discordam fortemente da afirmação são inexistentes.

Quadro 19 - Considero a compra pela internet fácil.

\begin{tabular}{|c|c|c|}
\hline Variações da Escala & Frequência & $\%$ \\
\hline Concordo fortemente & 71 & $59,2 \%$ \\
\hline Concordo & 47 & $39,2 \%$ \\
\hline Nem discordo nem concordo & 2 & $1,7 \%$ \\
\hline Discordo & 0 & $0,0 \%$ \\
\hline Discordo fortemente & 0 & $0,0 \%$ \\
\hline
\end{tabular}

Fonte: Elaboração dos autores.

Quando questionados sobre os aborrecimentos no processo de compra, 76 respondentes afirmam que a compra pela internet diminui os aborrecimentos no processo de compra, como visto no Quadro 20. Apenas 8,3\% dos respondentes discordam com a afirmação, 63,4\% concordam ou concordam fortemente, enquanto $28,3 \%$ optaram por não se posicionar frente ao exposto.

Quadro 20 - A compra pela internet diminuiu meus aborrecimentos com o processo de compra.

\begin{tabular}{|c|c|c|}
\hline Variações da Escala & Frequência & $\%$ \\
\hline Concordo fortemente & 35 & $29,2 \%$ \\
\hline Concordo & 41 & $34,2 \%$ \\
\hline Nem discordo nem concordo & 34 & $28,3 \%$ \\
\hline Discordo & 10 & $8,3 \%$ \\
\hline Discordo fortemente & 0 & $0,0 \%$ \\
\hline
\end{tabular}

Fonte: Elaboração dos autores.

Finalizando a análise do quinto construto avaliado neste instrumento, conclui-se que a compra pela internet é conveniente para os respondentes e bem aceita, considerando os baixos riscos percebidos avaliados anteriormente.

\section{CONSIDERAÇÕES FINAIS}

Esta pesquisa teve como objetivo analisar o comportamento de compra de mystery box na visão dos consumidores da Turista Literário. Os respondentes têm fortes intenções de adquirir uma mystery box. 0 valor agregado em uma mystery box torna a compra vantajosa, visto que os produtos enviados são em edições limitadas e personalizadas conforme os clubes de assinatura.

Foi verificado que o consumidor prefere adquirir produtos em uma mystery box e pagar um valor monetário superior, do que adquirir os produtos de forma avulsa e pagar um valor inferior. 0 consumidor tem conhecimento de que em muitas 
vezes torna-se mais caro adquirir uma mystery box em função dos produtos enviados serem personalizados, e sabe que se optar por comprar o mesmo produto diretamente em uma loja que o comercialize terá a opção de economizar com a compra, mas mesmo assim prefere adquirir uma mystery box e ser surpreendido a cada edição.

0 risco percebido não é um fator que influencia na decisão de compra deste público, visto que os respondentes consideram mínimo o risco de comprar uma mystery box. Além disso, atualmente, o comércio de mystery boxes é realizado quase que exclusivamente online, salvo em algumas empresas que comercializam suas caixas em lojas físicas também. Isso traz conveniência aos consumidores, que consideram este um fator importante na decisão de compra.

Este estudo possibilitou aos empreendedores do comércio de mystery boxes índices comprovados dos fatores que influenciam a decisão de compra do consumidor. Visto que é um estudo pioneiro, a partir deste tem-se um instrumento a fim de auxiliar na tomada de decisão dos gestores de clubes de assinatura de mystery boxes.

Como limitações deste estudo, destaca-se o fato de que as questões do instrumento não foram validadas para o contexto aplicado, bem como não foi realizado um cálculo amostral, o que impossibilita a generalização de resultados para a população de consumidores da empresa estudada. Sugere-se ampliar este estudo, com a realização da validação da escala utilizada, bem como ampliar a discussão dos resultados encontrados.

\section{REFERÊNCIAS}

BARBA. Citações e referências a documentos eletrônicos. Disponível em: <https://www.youtube.com/watch?v=EdlDg_VJLiA>. 2015. Acesso em 6 novembro. 2017.

CHURCHILL, Gilbert A.; PETER, J. Paul. Marketing: criando valor para o cliente. São Paulo: Saraiva, 2000.

ENGEL, J. F.; BLACKWELL, R. D.; MINIARD, P. W. Comportamento do consumidor. 8. ed. Rio de Janeiro: Livros Técnicos e Científicos Editora S.A, 2000.

LARÁN, J. A.; ROSSI, C. A. V. Surpresa e a formação da satisfação do consumidor. RAE-eletrônica. 2006.

MARTINS, Vitor. Citações e referências a documentos eletrônicos. Disponível em https://www.youtube.com/watch?v=PJEN15Jxi8c. 2016. Acesso em 27 outubro. 2017.

OLIVER, R. L. Processing of the satisfaction response in consumption: a suggested framework and research propositions. Journal of Consumer Satisfaction, Dissatisfaction and Complaining Behavior, vol. 2, p. 1-16, 1989

SOLOMON, Michael R. Consumer behavior: buying, having and being. Philadelphia: Pearson Education, 2015.

WESTBROOK, R. A. A rating scale for measuring product/service satisfaction. Journal of Marketing, vol. 44, p. 68-72, 1980. . Product/consumption-based affective responses and postpurchase processes. Journal of Marketing Research, vol. 24, p. 258-270, aug. 1987. 